\title{
Farmers' Survival Strategies in an Ethnic Conflict Situation in Two Villages in Vavuniya District of Sri Lanka
}

Jeyaseelan Gnanaseelan

Master of Science in Human Security

2004 
"The work described in this dissertation was carried out by me under the supervision of Dr. Krishan Deheragoda, Dept. of Geography, University of Sri Jayawardenepure and a report on this has not been submitted in whole or in part to any University for another Degree/Diploma."

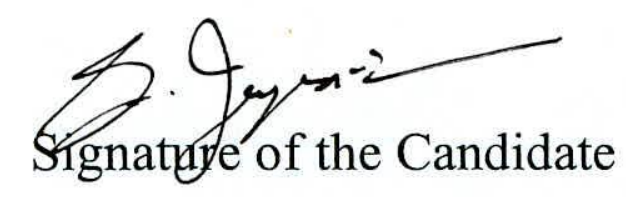


"I certify that the above statement made by the candidate is true and that this dissertation is suitable for submission to the University for the purpose of evaluation"

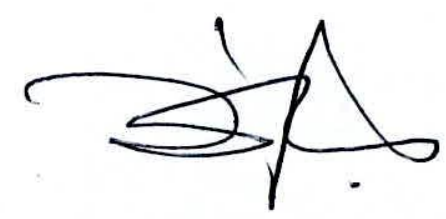

Signature of the Supervisor 


\title{
Farmers' Survival Strategies in an Ethnic Conflict Situation in Two Villages in Vavuniya District of Sri Lanka
}

\author{
By \\ Jeyaseelan Gnanaseelan \\ Reg.No.GS/SS/1478/2001
}

Dissertation submitted to the University of Sri Jayewardenepura for the award of the degree of Master of Science in Human Security 


\section{Table of Contents}

List of Illustrations-Maps, Tabies, Charts, Graphs and Figures............ iii Acknowledgement ........................................................ vi

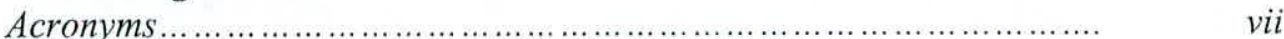
ABSTRACT .............................................................. viii

\section{Chapter}

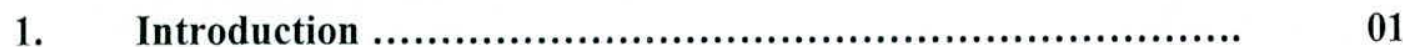

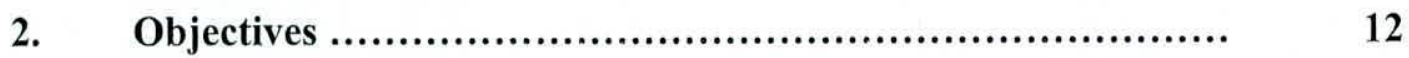

3. Literature Review of Conflict Constraints and Farmers' Livelihoods ....................................................... 14

3.1. General Global Background ................................. 14

3.2. Conflict and Farmers' Vulnerability............................ 17

3.3. Types of Conflict ............................................ 19

3.4. Demographics and Vulnerable Groups of the Wanni Region......... 26

3.5. The Conceptual Model of Survival Strategies....................... 28

3.6. The Conceptual Frame work of the Farmers' Survival Strategies............................................... 30

3.7. Household Livelihood Security Indicators.................... 33

3.8 Armed Conflict Strategies versus Farmers' Livelihood and Survival Strategies.

4. Research Methodology .................................... 52

4.1 Primary Data Collection ...................................... 55

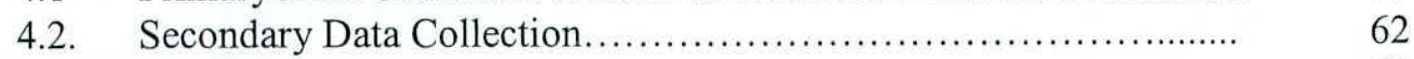

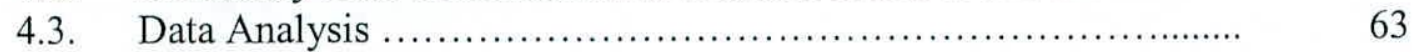

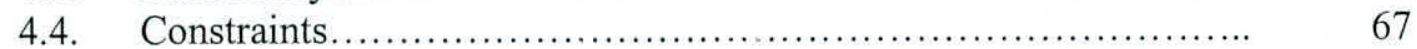

5. Socio-economic Background of the Study Area................ 71

5.1. The Vavuniya District........................................ 71

5.2. The Vavuniya D.S Division.................................. 71

5.3. The Villages under the Study............................... 74

6. Nature of the Livelihood Practices in the Conflict-affected Areas........................................................ 108

6.1. Administration and Political Issues.......................... 108

6.2. Livelihood and Social Issues................................. 110

6.3. Livelihood and Economic Issues................................ 118

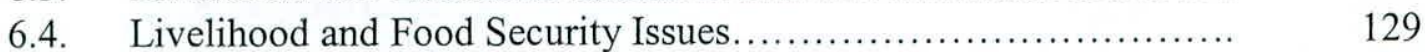

6.5. Livelihood and Health Security Issues........................ 132 
6.6. The Status of the Farmers in the Conflict Areas.................. 134

7. Survival Strategies......................................... 136

7.1. Farmers' problems.......................................... 136

7.2. Finding or living in a house.................................. 139

7.3. Land ownership and utilization............................... 144

7.4. Livestock ownership and utilization........................... 150

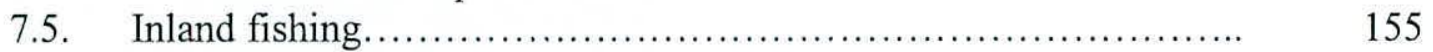

7.6. Owning and using agricultural implements...................... 156

7.7. Irrigation.................................................. 161

7.8. Obtaining credit facilities...................................... 165

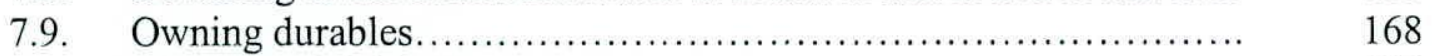

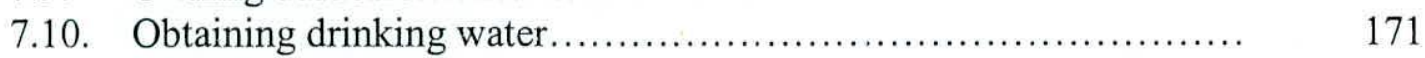

7.11. Conducting farming activities.............................. 172

7.12. Finding other sources of income............................. 187

7.13. Obtaining and consuming food................................ 190

7.14. Obtaining health care..................................... 195

7.15. Educating children........................................ 197

8. Conclusions............................................... 205

9. Recommendations........................................ $\quad 218$

References......................................................... $\quad 222$

Appendices........................................................ $\quad 227$

Data Collection Form ....................................... 227

Village Resource Mapping-Kovilkunchukulam................... 238

Village Resource Mapping-Poovarasankulam.................... 239

Human Resource and Social Mapping-Kovilkunchukulam.......... 240

Human Resource and Social Mapping-Poovarasankulam........... 241

KKK Socio-gram............................................ 242

PVK Socio-gram........................................... 243

The Explanation for the Tamil Terms Used in this Study.......... 244 


\section{List of Illustrations-Maps, Tables, Charts, Graphs and Figures}

\section{Maps}

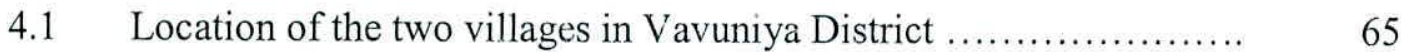

$5.1 \quad$ Vavuniya District.............................................. 72

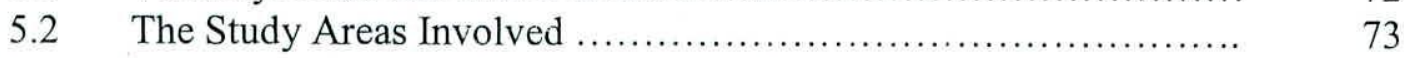

5.3 Poovarasankulam village in Vavuniya District .................... 75

5.4 Kovilkunchukulam village in Vavuniya District.................. 87

5.5 The routes people used to reach Vavuniya from KKK.............. 94

\section{Tables}

3.1 Year 2000 Population Estimates for the Wanni .................... 26

3.2 Survival Strategies and the Appraisals Which Evoke Them.......... 29

3.3 Nutritional Status in Selected Sri Lankan Communities.............. 33

4.1 Random Sampling- Kovilkunchukulam and Poovarasankulam ...... 55

4.2 Selection of the household in random.......................... 56

5.1 PVK Socio-gram Information .................................. 77

5.2 KKK Socio-gram Information ................................ 88

6.1 The Agricultural Inputs Used ................................. 125

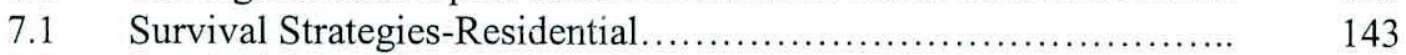

7.2 Survival Strategies-Land Use.................................. 146

7.3 Survival Strategies-Livestock Rearing......................... 152

7.4 Survival Strategies-The Use of Agricultural Implements............. 159

7.5 Survival Strategies-Irrigation Activities............................ 164

7.6 Survival Strategies-Credit Facilities............................. 167

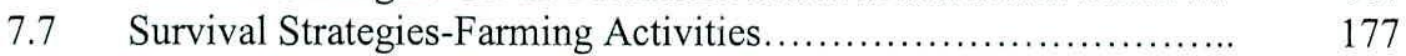

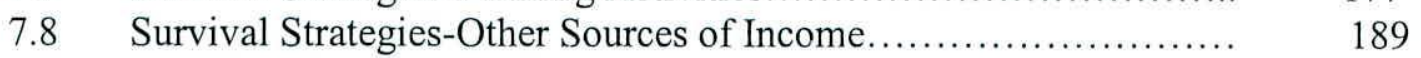

7.9 Survival Strategies-Food and Nutrition......................... 193

7.10 Survival Strategies-Health Care............................... 196

\section{Charts}

4.1 The Flowchart of the Research Methodology..................... 53

5.1 Tanks and paddy cultivation in PVK (BICP) ....................... 79

6.1 Dependency Rate............................................. 111

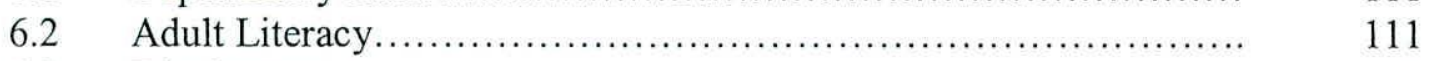

6.3 Displacement........................................... 112

6.4 Duration of Displacement................................... 113

6.5 Trend of Housing Pattern..................................... 114

6.6 School Education............................................... 117

6.7 Owning Fishing Gear and Nets.............................. 120

6.8 The Credit System Practiced.................................... 121

6.9 Durables Owned........................................ 123 
6.10 Adequacy of Irrigation........................................ 124

6.11 High land Cultivation in BICP................................... 127

6.12 Health Impacts............................................... 133

7.1 Paired Matrix Ranking of the Farmers' Problems................... 138

7.2 Paddy land Cultivation in BICP................................. 147

7.3 Paddy land Cultivation in DICP................................ 148

$7.4 \quad$ Livestock Rearing.................................................... 153

7.5 Selling or Buying Livestock ........................................ 154

7.6 Owning Agricultural Implements.................................. 157

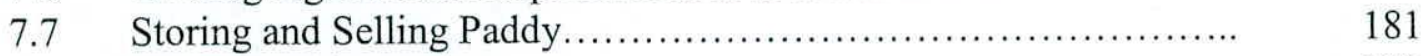

$7.8 \quad$ Selling Paddy Produce........................................... 182

$7.9 \quad$ Highland Cultivation in DICP................................... 184

$7.10 \quad$ Enhancing Farming Activities.................................... 186

7.11 Other Sources of Income.......................................... 187

7.12 Food Security and Survival Strategies............................. 194

\section{Graphs}

5.1 PVK and KKK Seasonal Calendar for Rainfall..................... $\quad 80$

$5.2 \quad$ Population Trend of PVK from 1987-2003 ........................ 81

5.3 Seasonal Calendar for Black Gram Cultivation....................... 102

5.4 Seasonal Calendar for Chilli Cultivation.......................... 103

5.5 Seasonal Calendar for Onion Cultivation............................. 103

5.6 Seasonal Calendar for Sesamum Cultivation......................... 104

5.7 Seasonal Calendar for Groundnut Cultivation........................ 104

5.8 Seasonal Calendar for Coconut Cultivation.......................... 105

$5.9 \quad$ Seasonal Calendar for Wedding .................................. 105

5.10 Seasonal Calendar for Shramadhana............................... 106

5.11 Seasonal Calendar for Religious Ceremonies........................ 106

5.12 Seasonal Calendar for Fasting ..................................... 107

6.1 Seasonal Calendar for Temperature................................ 124

6.2 Seasonal Calendar for Ploughing and Sowing....................... 126

6.3 Seasonal Calendar for Harvesting..................................... $\quad 126$

6.4 Seasonal Calendar for meat from Jungle........................... 130

6.5 Seasonal Calendar for Vegetables and Fruits from Jungle.............. 131

6.6 Seasonal Calendar for Human Diseases............................... 133

7.1 Seasonal Calendar for Mist and Dew.............................. $\quad 140$

7.2 Seasonal Calendar for Farmers' Workload........................... 151

7.3 Seasonal Calendar for Tank Irrigation.............................. 162

7.4 Seasonal Calendar for Agro-well Irrigation.......................... 163

7.5 Seasonal Calendar for Savings...................................... 168

7.6 Seasonal Calendar for Wind ......................................... 183

7.7 Seasonal Calendar for Income...................................... 189

7.8 Seasonal Calendar for Expenditure................................ 190

7.9 Seasonal Calendar for Food Shortage............................... 191

7.10 Seasonal Calendar for School Attendance.......................... 198 
7.11 Seasonal Calendar for Children Assisting

Parents in Farming.

\section{Figures}

3.1 The Conceptual Model of Survival Strategies .................... 28

3.2 The Conceptual Framework of the Farmers'

Survival Strategies in an Ethnic Conflict Situation................ 31

7.1 Inland Fishing in Tanks and Canals by Karappu.................... 156

7.2 Thrashing by Using Bulls and Wooden Roller..................... 160

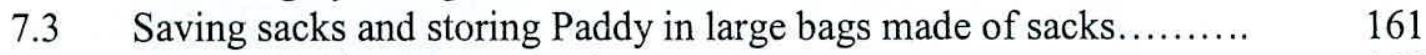

7.4 Saving Fuel in Pump Irrigation............................... 165

$7.5 \quad$ Umi Adduppu (Husk Oven).................................. 170

7.6 Sikkana Adduppu (Fuel-saving Oven)........................... 170

7.7 Steam Boiling of Paddy..................................... 176

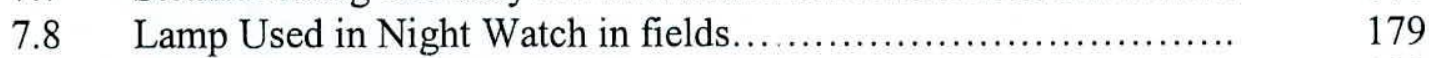

7.9 Sponge Lamp or Fuel Saving Lamp......................... 199 


\section{Acknowledgement}

I would like to dedicate this research work to all the poor and marginalized communities living in the conflict affected areas of Sri Lanka, in the hope that the information and insights contained in this study will some way, contribute to improve their lives.

I wish to thank all of the enumerated households, all the key informants, participants of the focus group discussions and all the organizations including Government Agents, $N G O$ representatives etc, who have made an immense contribution to make this study a success.

Special appreciation goes to Dr. Krishan Deheragoda, supervisor of my research and the course coordinator of this Msc programme in Human Security. Further I would like to thank senior professor M.M.Karunanayake, professor Y.A.D.S. Wanasinghe and the former coordinator of this programme, and Professor M.D.C. Abhayaratna, of the Dept. of Geography for initiating this Master's programme and their continued guidance and support to me during the course period and research.

Very special thank you goes to Mr. Suthakar, Research Officer, Regional Agricultural Research Centre, Mr.Umapathy,UNDP, Vavuniya, Mr. S. Krishnakumar lecturer, Vavuniya Campus for their continued support to the research under very difficult circumstances in Vavuniya district. The study would not have been possible without the moral and intellectual support of all the lecturers who taught me and all the other Geography Department staff, University of Sri Jayewardenepura for assistance to this study and The enumeration team consisting of Tharmendra, Thiirukkumaran ,S. Santhiramohan, My brother G.Vasanthseelan and A. Armstrong deserves very special recognition for their continued interest, commitment, and patience as well maintaining a sense of humor during the data collection.

Last but not least, special gratitude goes to my dear wife, Subajana for her valuable care on my physical and psychological welfare throughout the study. 


\section{Acronyms}

AGA-Assistant Government Agent

$B I C P$ - Before the Intensive Conflict Period

$C A R E$ - Cooperative for Assistance and Relief Everywhere

$C B O$ - Community-based Organization

CFA - the Ceasefire Agreement

DICP-During the Intensive Conflict Period

D.S- the Divisional Secretariat

GSL - Government of Sri Lanka

GSO - Grama Sevaka Officer

HH - Household

HLS - Household Livelihood Security

HSZ- the High Security Zones

ICRC - International Committee of the Red Cross

IDPs - Internally Displaced Persons

INGO - International Non-governmental Organization

KKK-Kovilkunchukulam

LTTE - Liberation Tigers of Tamil Eelam

MOU- the Memorandum of Understanding

MPCS - Multi Purpose Cooperative Society

MSF- Medicine sans Frontier

NECORD- the Northeast

NEIAP the Northeast Irrigation and Agriculture Project

$N G O$ - Non-governmental Organization

PVK-Poovarasankulam

RDS - Rural Development Society

SLA - Sri Lankan Army

SLRC-Sri Lanka Red Cross

TCCS - Thrift and Credit Cooperative Society

TEEDO - Tamil Eelam Economic Development Organization

TRO - Tamil Rehabilitation Organization

UNDP - the United Nations Development Programs

UNHCR - United Nations High Commissioner for Refugees 


\title{
Farmers' Survival Strategies in an Ethric Conflict Situation in Two Villages in Vavuniya District of Sri Lanka
}

Jeyaseelan Gnanaseelan

\begin{abstract}
This research examines the survival strategies practiced by the farmers in the two villages of the Vavuniya District of Sri Lanka during the intensive conflict period(DICP means from 1990 onwards), which is compared and contrasted with the traditional livelihood systems of these farmers before the intensive conflict period (BICP means before 1990); it studies the causes of their survival strategies and relates them to the perceptions of the farmers and its consequence on their lives; it describes the prevalent livelihood systems such as housing trend and residential patterns, cultivation land ownership and utilization both paddy and highland, livestock rearing, use of agriculture implements and inputs, irrigation, credit and saving facilities and systems, owning and using durables, farming activities both Maha and Yala, highland cultivation, and home gardening, other sources of income generation, drinking water, food security and nutrition, and health care as they existed before and after 1990 and identifies the survival strategies and techniques adopted in each livelihood system mentioned above against the constraints from 1990 onwards; it characterizes the vulnerable groups and investigates the extent of vulnerability, marginalization, dispossession, accumulation, and unsustainability caused by the conflict
\end{abstract}

It illustrates the process of change in forming survival strategies by revealing the ways in which the farmers were engaged in negotiation, bargaining, and struggle which could alter their circumstances; it determines the current status of social networks and civil societies and CBOs and assesses the government, the forces, the militants, the NGOs and other civil societies 'interventions in farmers' livelihood and survival; it critically synthesizes the adoptable survival strategies primarily based on the practices and perceptions of the farmers in two villages of this district. 


\section{Introduction}

Farmers' survival strategies in a conflict situation have been rarely touched in Srilankan studies in the past except some small surveys for institutional interventions by both international and local NGOs. Even in international literature so much importance has been given to the details of the impacts of the conflicts and of the conflicts themselves not the survival and coping strategies of the farmers specifically. In general terms, this study provides an overall picture of survival, livelihood and vulnerability of farming communities with regard to economic, food and other key human security aspects. The future institutional interventions can respond to the most critical needs of those communities. The study attempts to identify and describe groups of greatest vulnerability (e.g. farmers, women, IDPs) and analyzes causes contributing to their vulnerability and survival. In addition, assets, opportunities and institutional resources were identified and analyzed.

The purpose and objectives of this research lend themselves to both qualitative and quantitative methodologies, which covered the two village sites selected in much greater depth. This approach provided adequate information for a comprehensive understanding of the situation seen from different perspectives and the information were obtained in a participatory manner. A variety of research tools were employed during data collection including large and focus group discussions, historical profiles, key informant interviews, and household surveys. Numerical data were collected during household questionnaire and interviews to allow quantitative estimates to be made. 
The communities included within the sampling frame were stratified based on major livelihood, agricultural potential, demographic situation, and district. This allowed a selection of sites representative of the vast majority of the overall study area within the Wanni region. Ultimately, low potential agricultural communities were selected in the Divisional Secretariat area of the Vavuniya district. Households were selected at random in each community on each livelihood category. The IDPs in the villages and in settlements attached to existing communities represent the most significant vulnerable group in the Wanni. Estimates were that more than 200,000, people were living in welfare centers, settlement schemes and mixed communities throughout the Wanni in 2000. The inadequacy of their monthly ration, combined with a lack of productive assets and shortage of wage labor opportunities make them highly food and income insecure.

The two village agricultural communities revealed that the low potential communities have lesser access to water for irrigation. While the farmers faced the same constraints, i.e. shortages and high prices of fertilizers and other inputs, poor access to markets, etc., Low potential farmers, however, were barely surviving and resorted frequently to coping mechanisms such as changes in diet and sale/mortgage of assets to get through difficult times. The conflict affected all groups in the Wanni (e.g. prices for basic commodities were generally 2-5 times higher here than in the South) but might have the greatest economic impacts on farming communities. Farmers were excluded from productive farming zones, could not transport their harvest to lucrative markets, must pay artificially high prices for inputs and fuel, and lived in communities that were 